\title{
Editor Note: Single Cell Biology
}

\section{Yusuf Tutar*}

Faculty of Pharmacy, Department of Basic Sciences, Biochemistry Division, Cumhuriyet University, Turkey

*Corresponding author: Yusuf Tutar, Faculty of Pharmacy, Department of Basic Sciences, Biochemistry Division, Cumhuriyet University, Turkey, Tel: 03462191010; Email: ytutar@outlook.com

Rec Date: Jun 24, 2016; Acc Date: Jun 27, 2016; Pub Date: Jun 29, 2016

Copyright: (c) 2016 Tutar Y. This is an open-access article distributed under the terms of the Creative Commons Attribution License, which permits unrestricted use, distribution, and reproduction in any medium, provided the original author and source are credited.

\section{Editorial}

The current issue (Volume 5, Issue 2) of Single Cell Biology contains 11 articles, which consist of one Research Article, two mini reviews, one perspective, one short communication and six commentary articles. For your convenience, below are a few words to let you know what I think you can expect from each of these articles.

Cystic fibrosis $(\mathrm{CF})$ is one of the most frequent autosomal recessive diseases in the Caucasian population and is due to CF transmembrane conductance regulator (CFTR) dysfunction. Thus, this study illustrates the need for data from multiple sources to be taken consideration when CFTR mutations are classified. Moreover, the classification of a mutation is not sufficient to inform the clinical approach, as the presence of complex allele may alter the specific effect of a single mutation [1].

A mini review by Luna-Ramírez $\mathrm{K}$, et al. discussed regarding the interesting compounds of scorpion venom that might aid against the fight towards multi-resistant drug bacteria, contribute to the understanding of potassium ion channels, control viral replication and help in combating malaria. This effect is due to the bi-functionality of scorpine-like peptides [2].

Survivin is a member of the inhibitor of apoptosis, gene family and is markedly overexpressed exclusively in cancers but not in normal adult tissues implying that it could be an ideal target for cancer directed therapy. Survivin promoter has been shown to be highly specific for tumor cells and tissue in vitro and in vivo in several studies, having a therapeutic potential in gene therapy which is well described by Vachtenheim J, et al [3].

Perspective article by Lejeune $\mathrm{F}$ discussed regarding the inhibition of NMD in cancer cells can restore expression of PTC containing tumor suppressor genes, allow the synthesis of harmful truncated proteins in cancer cells, and cause induction of an anticancer immune response. The method used to induce NMD inhibition should be crucial to preventing the activation of cell defenses such as autophagy or the ER stress response [4].

Nunez-Andrade N, et al. discussed regarding the viral infections involves specific stress exposure that can influence the quality and average lifespan of an organism. Many aspects of immune cells accounting for this response are still under study and hence they provided recent aspects of the molecular mechanisms involved in the delivery of the lethal hit by Cytotoxic T lymphocytes [5].

The commentary by Yusuf $\mathrm{M}$, et al. gives the information on future Prospects of 3D Human Chromosome Imaging by Serial Block Face Scanning Electron Microscopy. This would reduce the damage rate by preventing the diffusion of free radicals. Cryo-FIB has been used for cell imaging and is yet to be experimented on human chromosomes in a single cell [6].
Maria L, et al. discussed regarding the transgenic Mouse Models for the Therapeutic Use of dynamin-related protein 1 Inhibitors. Pharmacological inhibition of Drp1 the main mammalian promoter of mitochondrial fission - has emerged as a promising therapeutic target for the treatment of neuronal injuries which has led to new insights into the importance of mitochondrial fission in differentiated neurons and has highlighted potentially severe side effects of this new therapeutic strategy [7].

Commentary article by Fukuda T, et al. described regarding the Amelogenin, the major component of a commercial enamel matrix derivative, is commonly employed in periodontology. It is mainly used in periodontal surgery to stimulate the regeneration of periodontal tissues, including the cementum, periodontal ligament, and alveolar bone. Although the potentiation effects of Grp78 should be further examined in vivo, their findings indicate the significant therapeutic potential for amelogenin-induced periodontal tissue regeneration [8].

Lebeaupin C, et al. described regarding the role of ER Stress in Inflammasome Activation and Non-Alcoholic Fatty Liver Disease Progression which has become the most common form of chronic liver disease and contribute substantially to chronic liver disease progression as important triggers of cell death and inflammation, and therefore may represent potential therapeutic strategies [9].

Castro A and Lorca $\mathrm{T}$ discussed regarding the activation of protein kinases and phosphatases that regulate key cell cycle components allowing entry, progression and exit of mitosis. This commentary summarizes recent data on the regulation of Greatwall activity and reversal of mitotic substrates phosphorylation required for mitotic exit [10].

Commentary by Aoki $\mathrm{H}$, et al. gives information on RE1-silencing transcription factor which is a negative regulator of neuron-specific genes and expressed during embryonic development to prevent neural gene expression in non-neuronal cells. These results suggested the expression of RE1-silencing transcription factor during the early NCC specification stage is necessary for the proper development of neural crest cells [11].

\section{References}

1. Ladeveze V, Farhat R, El Seedy A, Kitzis A (2016) Multi-Functional Consequences of a Single Mutation of CFTR of the Importance to Analyze Mutations by Functional Tests. Single Cell Biol 5: 142.

2. Luna-Ramírez K, Jiménez-Vargas JM, Possani LD (2016) Scorpine-Like Peptides. Single Cell Biol 5:138.

3. Vachtenheim J, Vlckova K (2016) Insights into the Regulation of Survivin Expression in Tumors. Single Cell Biol 5:139.

4. Lejeune F (2016) Triple Effect of Nonsense-Mediated mRNA Decay Inhibition as a Therapeutic Approach for Cancer. Single Cell Biol 5:136. 
5. Nunez-Andrad N, Sanchez-Madrid F, Martin-Cofreces NB (2016) HDAC6 is a Regulator of CTL Function through Control of Lytic Granule Dynamics. Single Cell Biol 5: 143.

6. Yusuf M, Chen B, Robinson I (2016) Future Prospects of 3D Human Chromosome Imaging by Serial Block Face Scanning Electron Microscopy. Single Cell Biol 5:134.

7. Maria L, Björn O (2016) Lessons Learned from Transgenic Mouse Models for the Therapeutic Use of Drp1 Inhibitors. Single Cell Biol 5:135.

8. Fukuda T, Sanui T, Toyoda K, Tanaka U, Yamamichi K, et al. (2016) Glucose- Regulated Protein 78: A Novel Therapeutic Target for
Amelogenin-Induced Periodontal Tissue Regeneration. Single Cell Biol 5:137.

9. Lebeaupin C, Vallee D, Gual P, Bailly-Maitre B (2016) Role of ER Stress in Inflammasome Activation and Non-Alcoholic Fatty Liver Disease Progression. Single Cell Biol 5:140.

10. Castro A, Lorca $T$ (2016) Protein Phosphatases Triggering the Dephosphorylation and Inactivation of Greatwall. Single Cell Biol 5: 141.

11. Aoki H, Kunisada T (2016) Rest as a New Transcription Factor to Control Neural Crest Development. Single Cell Biol 5: 144. 